\title{
El nemátodo entomopatógeno Steinernema carpocapsae para el control biológico de la plaga Sagalassa valida Walker en palma aceitera Elaeis guineensis: Una alternativa al uso de pesticidas químicos
}

\author{
Victor Antonio Oliva Aragón \\ Técnico en Producción Agrícola \\ Gesly Anibal Bonilla Landaverry \\ Ingeniero Agrónomo, Maestro en Ciencias en Gestión Ambiental y Doctor en Ciencias Políticas y Sociología \\ gesly77@hotmail.com \\ Centro Universitario de Sur Oriente \\ Universidad de San Carlos de Guatemala
}

Fecha de recepción: 18/07/2014

Fecha de aprobación: 02/10/2014

\begin{abstract}
Resumen
Dentro de la demanda de grasas, aceites y derivados oleaginosos, los provenientes de la palma africana son los de mayor consumo, y se prevé que esta tendencia se mantendrá por un largo período de tiempo. Guatemala cuenta con alrededor de 120,000 hectáreas establecidas con palma aceitera Elaeis guineensis Jacq, de las cuales 106,000 se encuentran en producción con 347 palmicultores, que en su mayoría son grandes productores (59\%), demostrando la importancia socio-económica que este cultivo representa para la generación de empleo, de manera directa e indirecta, y por su potencial como biocombustible. A pesar de su importancia, el rendimiento de aceite es bajo, estimándose un promedio mundial de 3.2 TM/ha. Los bajos rendimientos que presenta este cultivo podrían deberse a los problemas de plagas y el mal manejo de los suelos. La palma aceitera es susceptible a ataques de plagas y enfermedades, y dentro del complejo de insectos que afecta a este cultivo, el barrenador de las raíces, Sagalassa valida Walker (Lepidóptera: Glyphipterigidae), es sin duda una de las plagas con mayor importancia económica y posiblemente la de más difícil manejo en Guatemala. Aunque su ataque aun no produce grandes pérdidas, es conveniente controlarlo antes que sea más difícil de erradicar. En la actualidad Sagalassa valida ha sido reportado con alta incidencia en la región del Polochic, en Guatemala afectando considerablemente a una de las más importantes zonas productoras, razón por la cual se busca una alternativa biológica y ambientalmente amigable de control que permita reemplazar el uso del Endosulfan, químico que por ahora representa la única alternativa eficaz para su control. Una alternativa de control biológico puede ser el nemátodo entomopatógeno Steinernema carpocapsae.
\end{abstract}

Palabras clave: Palma africana, pesticidas, control biológico, contaminación ambiental, nemátodos

\begin{abstract}
Within the demand for fats, oils and oil derivatives, from African palm are the most consumed, and it is expected that this trend will continue for a long period of time. Guatemala has around 120,000 hectares established oil palm Elaeis guineensis Jacq, of which 106,000 are in production with 347 palm growers, most of whom are large producers (59\%), demonstrating the socio-economic importance of this crop accounts for generating employment, directly and indirectly, and its potential as a biofuel. Despite its importance, the oil yield is low, estimated a global average of 3.2 MT / ha. Low yields having this crop could be due to pest problems and poor soil management. Oil palm is susceptible to attack by pests and diseases, and within the complex of insects that affect this crop borer roots, Sagalassa valida Walker (Lepidoptera: Glyphipterigidae) is undoubtedly one of the plagues most economically important and possibly more difficult to manage in Guatemala. Although his attack still does not produce large losses, it is desirable to control it before it is more difficult to eradicate. Currently Sagalassa valida has been reported with high incidence in the region of the Polochic, impacting on one of the most important producing areas, why seek a biological and environmentally friendly alternative of controls to replace the use of Endosulfan, chemical that now represents the only effective means of controlling. An alternativ for a biology controlling of nematodes may be Steinernema carpocapsae.
\end{abstract}

Key words: Palm oil, pesticides, biological control, environmental pollution, nematodes 


\section{Introducción}

El valle del Polochic, ubicado entre los departamentos de Izabal y Alta Verapaz, se encuentra cultivado en su mayor parte con palma africana Elaeis guineensis Jacq, utilizada para la extracción de aceite vegetal comestible y otros derivados. El valle presenta condiciones climáticas y edáficas que hacen que la planta se desarrolle de manera óptima, alcanzando una producción de hasta $30 \mathrm{TM} / \mathrm{ha} / \mathrm{año}$ de fruta, con una densidad de siembra de 143 plantas/Ha.

La presente investigación se desarrolló en condiciones de campo en el municipio de El Estor, departamento de Izabal, utilizando un lote sembrado con material Avros de tres años de trasplante al campo, con las condiciones necesarias para la investigación. Se evaluaron tres dosis de nemátodos Steinernema carpocapsae: una dosis baja de 750,000 nemátodos/palma, una dosis media de 1,500,000 nemátodos/palma y una dosis alta de 2,000,000 de nemátodos/palma, que se compararon con un producto químico (Endosulfan $10 \mathrm{cc} /$ palma) y un testigo absoluto. A nivel de campo los tratamientos se distribuyeron en un Diseño Completamente al Azar (DCA) con cinco repeticiones.

El objetivo principal de la investigación fue reducir el uso de pesticidas para el control de Sagalassa valida $W$., debido a que por normas de certificación debe usarse un control biológico de plagas, el cual se supone que puede lograrse con distintas dosis de nemátodos para el control de las larvas.

\section{Planteamiento del problema}

Entre las causas que producen un bajo rendimiento de cultivares jóvenes de palma aceitera en Guatemala están las plagas, especialmente de insectos, que afectan considerablemente la producción $y$, consecuentemente, la competitividad del sector productivo. El barrenador de las raíces Sagalassa valida $W$. es una plaga de importancia para la palma aceitera en la región; su incidencia es evidente en las tres zonas de mayor producción que son: valle del Polochic, Franja Transversal del Norte y El Petén.

La gravedad del daño provocado las larvas de Sagalassa valida W., que al vivir en el sistema radical pasan desapercibidas, sólo se manifiesta cuando han afectado hasta el $80 \%$ de las raíces. El daño ocasionado por las larvas consiste en barrenaduras o galerías que pueden alcanzar más de $30 \mathrm{~cm}$ de longitud.

Como consecuencia del ataque las palmas afectadas pueden tener mal anclaje, produciendo en casos extremos volcamiento; además, se presentan alteraciones fisiológicas que se reflejan en mal desarrollo, lento crecimiento, amarillamiento y secamiento prematuro de las hojas basales e intermedias, así como emisiones continuas y prolongadas de inflorescencias masculinas, unidas a una reducción en el tamaño de los racimos.

Las empresas productoras de palma, en su afán de controlar la plaga, han recurrido principalmente a insecticidas químicos, realizando aplicaciones dirigidas a la corona cerca del estípite de la palma. El ingrediente activo de los productos ha sido principalmente el Endosulfan, un insecticida organoclorado perteneciente a la clase toxicológica I (etiqueta roja), que tiene una dosis letal media (DL50) oral de 18-110 $\mathrm{mg} / \mathrm{kg}$ y una DL50 dermal de $74-130 \mathrm{mg} / \mathrm{kg}$; por ese motivo ha sido clasificado como un plaguicida extremadamente tóxico y por razones de certificación ya no puede ser usado por los productores.

El uso de químicos siempre presenta un riesgo para la salud humana, contamina los recursos suelo y agua, y ocasiona la muerte de otros insectos considerados benéficos, como los polinizadores. Por esta razón es necesario evaluar otras alternativas, tales como el uso de organismos entomopatógenos como Steinernema carpocapsae, para realizar un manejo ecológicamente 
aceptable y efectivo para el control biológico de las larvas de Sagalassa valida $W$.

\section{Objetivos}

\section{GENERAL:}

Desarrollar una alternativa biológica para el control del "Barrenador de la raíz" Sagalassa valida $W$. en el cultivo de la palma africana mediante el uso de nemátodos entomopatógenos.

\section{ESPECÍFICOS:}

- Identificar la concentración de nemátodos más efectiva para el control del barrenador de la raíz en el cultivo de palma africana

- Evaluar la eficiencia de los nemátodos sobre el control Sagalassa valida, a nivel de campo.

\section{Hipótesis}

Al menos una concentración de nemátodos entomopatógenos Steinernema carpocapsae es eficiente en el control del barrenador de la raíz Sagalassa valida.

\section{Marco teórico}

\subsection{El cultivo de palma aceitera en Guatemala}

La palma de aceite es uno de los cultivos que sustituyeron la siembra de algodón en la década de los años ochenta en Guatemala. Luego de la búsqueda de diversas opciones que sustituyeran aquél cultivo, se comprobó que la palma de aceite ofrece más ventajas: es la más eficiente, es social y ambientalmente sostenible y genera empleo permanente por ser un cultivo perenne y porque el corte del fruto no es mecanizable.

La palma de aceite se ha desarrollado en el país en los últimos 24 años. En 1988 se registra el inicio formal de la siembra de palma de aceite en áreas antes destinadas al algodón, y en los años 1991 y 1992 que se cosecharon los primeros frutos de este cultivo. Las zonas aptas se encuentran principalmente en la costa sur y en el nororiente (departamentos de Izabal y Alta y Baja Verapaz, especialmente en los valles de los ríos Motagua y Polochic), así como en los departamentos de Quiché y en el sur del departamento de Petén (GREPALMA, 2013).

El cultivo se ha establecido especialmente en zonas que antes eran dedicadas a la ganadería o a la producción de otros cultivos como algodón y banano. En Guatemala, un país de $108,889 \mathrm{~km}^{2}$, la tierra de uso agrícola cubre un $58.12 \%$ del territorio nacional. De esta área, el $45 \%$ está sembrado con granos básicos (maíz blanco y frijol negro), un 17\% con café y un $12 \%$ con caña de azúcar.

En el 2005 la cobertura de palma africana en Guatemala era de 38,094 hectáreas y en 2010 se estimó en 93,513 (Duarte, et al., 2012). Al 2013 la palma de aceite ocupaba 120,000 hectáreas, es decir, alrededor del 4\% del total de la tierra cultivable del país. La agroindustria de la palma de aceite ha sido la fuente más eficiente en la producción de aceites en el mundo, debido a que produce más aceite por hectárea, requiriendo menos tierra y espacio que otros cultivos oleaginosos; además, es ambiental y socialmente sostenible. Por esta razón la palma se ha convertido en una opción de desarrollo para muchos guatemaltecos.

La realidad agraria del país y la escasez de la tierra exigen ser más eficientes en el uso de la tierra, minimizando los impactos socioambientales. En este sentido se considera que Guatemala tiene una buena productividad por hectárea. El país produce alrededor de 350 mil toneladas de aceite crudo de palma y se consumen 278 mil toneladas en diversos alimentos y productos. La totalidad de la producción del país se comercializa con fines de consumo humano, cubriendo la demanda local y exportando el excedente a otros países.

La palma contribuye al fortalecimiento de la industria de grasas y aceites en Guatemala, 
beneficiando a la población por el acceso a este producto a un precio razonable, contribuyendo de esta manera con la seguridad alimentaria del país. La dieta humana requiere de grasas que están contenidas en panes y galletas, entre otros productos comestibles, los cuales utilizan aceite de palma para su elaboración (GREPALMA, 2013).

\subsection{Utilización de microorganismos en el control de plagas}

De acuerdo con Jiménez y Calvache (1992), con el estudio de la patología de insectos se abre un nuevo campo en el control de plagas, el control microbial, el cual constituye otro elemento en el manejo integrado mediante el empleo de organismos entomopatógenos específicos. Esta forma de control se basa en observaciones muy antiguas que han demostrado que los insectos, al igual que todos los seres vivientes, son afectados por diferentes enfermedades.

Según Valencia (2003), la aplicación del control microbial se basa en general en los conocimientos sobre las propiedades patológicas y epizootiológicas de los organismos, considerando tanto las características ecológicas del medio en que se desarrolla el huésped como las necesidades agronómicas y económicas del cultivo.

El uso de agentes vivos (bacterias, virus, hongos, nemátodos) para el control de insectos plaga puede ser muy útil para suplir a los productos químicos, pero como todo sistema de control tiene ventajas y desventajas, como las que se mencionan a continuación.

Ventajas: a) poca o ninguna patogenicidad para animales benéficos y poca destrucción del balance natural; b) seguridad sanitaria: la mayoría de los patógenos no son peligrosos para los mamíferos incluyendo al hombre; c) se han registrado muy pocos casos de plagas resistentes a los patógenos; d) algunos persisten en la naturaleza sin aplicación adicional; y e) la mayoría son específicos a sus huéspedes (aunque no todos los patógenos son específicos en cuanto a sus huéspedes).

Desventajas: a) la velocidad con que se produce el efecto es generalmente lento; b) dificultades para mantener la virulencia por largo tiempo (problemas de almacenamiento del producto formulado); c) su efectividad depende mucho de las condiciones ambientales; y d) la calidad de los productos son posiblemente la causa de los problemas sanitarios.

\subsection{Factores que intervienen en el control biológico.}

Debach (1978), manifiesta que el aislamiento y el estudio de las características de los microorganismos es imprescindible para comenzar un trabajo de control. Las investigaciones han avanzado rápidamente, se han encontrado bacterias, hongos, virus, protozoarios, nemátodos y otros organismos causales de enfermedades en insectos de diferentes órdenes de importancia económica.

Factores biológicos: el empleo de estos microorganismos en la producción de cultivos se basa en los conocimientos adquiridos sobre los procesos patológicos que determinan la evolución de las enfermedades del estado enzoótico (estado de ocurrencia continua de una enfermedad en animales con respecto a un patógeno en particular) hacia el estado epizoótico, por intervención o no del hombre. Estos fenómenos están relacionados con la agresividad del inóculo o el poder patogénico del organismo en estudio, la receptividad del huésped y la acción del medio en que se desarrolla. Obviamente es primordial que los organismos a utilizar sean altamente patogénicos para la plaga a controlar (Jiménez y Calvache, 1992).

Sensibilidad del insecto: comprende el estado fisiológico, el tipo de insecto, la edad, sexo, comportamiento, grado de resistencia o susceptibilidad. El comportamiento del 
insecto incide igualmente en el desarrollo y diseminación del inóculo; por ejemplo, en los insectos de hábito gregario hay mayores posibilidades de que la enfermedad se propague más rápidamente que en los insectos de vida solitaria

Los factores del medio ambiente (temperatura, humedad, radiación etc.) influyen tanto sobre el inóculo como sobre el insecto, y a su vez en el desarrollo de la enfermedad de éste.

En cuanto a los factores ambientales que intervienen en la generación de una epizootia, el más determinante es la temperatura, ya que influye de manera directa en la susceptibilidad del huésped y la multiplicación del patógeno dentro del mismo (Valencia, 2003).

En cuanto a las propiedades ecológicas, lo ideal en el control de los insectos mediante organismos microbiales es introducir un agente de regulación permanente del insecto plaga, para mantener las poblaciones por debajo del nivel del daño establecido para un cultivo. Por esto es necesario tener en cuenta los elementos que intervienen en el desarrollo de las enfermedades: insecto, organismo patógeno y condiciones del medio en el cual se efectúa la dispersión del patógeno (Jiménez y Calvache, 1992).

Esto último implica tener en cuenta el tipo de cultivo considerado (perenne, transitorio o semiperenne) y las condiciones ambientales del medio. El patógeno introducido entra en ocurrencia con los demás factores biotécnicos de regulación de la población hospedera (entomófagos, parásitos y otras enfermedades) y su aplicación se debe hacer cuando el estado biológico de la especie, su población y las condiciones ambientales, permiten obtener un resultado satisfactorio en la reducción del nivel de población.

Factores agronómicos: los conocimientos del microbiólogo, las condiciones del patógeno y el punto de vista del ecólogo no están siempre de acuerdo con las necesidades del agrónomo y el agricultor. Por consiguiente, el empleo de un organismo patógeno en el control de determinado insecto debe obedecer a un estudio cuidadoso de las necesidades de control, de su relación con otras alternativas y de la economía de su empleo.

La acción enzoótica a largo plazo es a veces incompatible con la protección de la cosecha, bien sea cuantitativamente en función de tasa mínima de sobrevivencia del insecto y el límite de tolerancia del cultivo, como cualitativamente en función de las normas de comercialización (Jiménez y Calvache, 1992).

\subsection{Propiedades que deben tener los organismos entomopatógenos}

Para Valencia (2003), una de las principales propiedades de estos organismos para la protección de cultivos es la especificidad que permite su utilización con la seguridad de no estar causando daño a otros organismos vivos distintos a las plagas, especialmente al hombre; además, tiene que ver la de la permanencia del organismo, pues este puede quedarse en el ambiente después de ser liberado y es deseable una alta permanencia, lo cual se logra en algunos casos, pero en muchos otros su biodegradabilidad por factores ambientales como la luz y la temperatura limitan su empleo para el control de la plaga.

La condición biológica que le da a un microorganismo sus características de plaguicida depende de las relaciones existentes entre el patógeno, el hospedero y las condiciones ambientales, así como de características intrínsecas del microorganismo, lo cual es sumamente variable.

Finalmente, la inocuidad ambiental, como característica propia de los seres vivos, hace a los microorganismos elemento óptimo para el control de plagas desde el punto de vista ecológico. Puede decirse que esta es la mejor característica del control microbiológico de plagas (Martignoni, 1979). 


\subsection{Nemátodos entomopatógenos para el control de Sagalassa valida $W$.}

De acuerdo con Sáenz y Betancourt (2006), los nemátodos entomopatógenos que han demostrado importancia en el control biológico de plagas corresponden a las familias Steinernematidae y Heterorhabditidae, cuyos miembros están mutualísticamente asociados (tipo de asociación entre dos individuos en que ambos obtienen beneficio) con bacterias de los géneros Xenorhabdus y Photorhabdus, que ocasionan septicemia (condición mórbida causada por la invasión y multiplicación de microorganismos en la hemolinfa) y otros tipos de afecciones letales en sus hospederos.

Entre las características que hacen de éste un grupo promisorio de controladores biológicos pueden destacarse las siguientes: alta virulencia y rápida acción al matar al hospedero; el tercer estado o juvenil infectivo no se alimenta; está morfológica y fisiológicamente adaptado para sobrevivir por largos períodos en el suelo en ausencia de su hospedero; tiene un alto potencial reproductivo y muestra respuesta numérica con respecto al hospedero; pueden criarse masivamente en laboratorio; tienen un amplio rango de acción, aunque algunos son muy poco específicos; alta resistencia a productos químicos y a condiciones ambientales adversas. Tanto los nemátodos entomopatógenos como sus bacterias son inocuos para humanos y animales domésticos; no causan daño a las plantas por ser específicos para insectos; y algunas especies se pueden reproducirse sin la presencia del macho.

Sáenz y Betancourt (2006) indican que dentro de los atributos negativos está incluidos: amplio rango de hospederos; limitada tolerancia a condiciones ambientales (requerimientos de humedad; tiempo corto de almacenamiento; pobre persistencia en campo; y altos costos de producción en comparación con los pesticidas químicos.

En cuanto a su ciclo de vida, de acuerdo a Jaime et al. (1992), los steinernematidos y heterorhabditidos tienen un ciclo de vida simple: huevo, cuatro estados juveniles y adulto. Los estados juveniles están separados por mudas. El estado infectivo corresponde al tercer estado juvenil especial (J3), que se conoce también como juvenil infectivo (IJ), y es especialmente resistente a las condiciones ambientales. Parece que su fisiología y la doble cutícula que los recubre le confieren esa condición de resistencia al medio ambiente. Además, es la única forma que vive libre fuera del hospedero, no se alimenta y gracias a las reservas de energía, derivadas de carbohidratos, pueden sobrevivir durante largos períodos cuando las condiciones de humedad y temperatura le son favorables. Se denomina infectiva porque contiene células vivas de las bacterias Xenorhabdus en su intestino y lo lleva de un insecto huésped a otro.

Los juveniles infectivos localizan al huésped y penetran en él a través de las aperturas del cuerpo: boca, ano, espiráculos. En forma activa atraviesan las paredes del intestino medio 0 de las tráqueas para llegar al hemocele. Allí inoculan la bacteria, la cual crece rápidamente y mata al insecto por septicemia dentro de las primeras $24-48$ horas. Los nemátodos inmaduros se alimentan de las células bacteriales y tejidos del insecto huésped hasta alcanzar el estado adulto. La primera generación de adultos es más grande que cualquiera de las sucesivas, talvez por la disponibilidad de mayor cantidad de alimento. La progenie de la siguiente generación, en muchos casos, encuentra agotado el suplemento alimenticio y entonces forman los nuevos juveniles infectivos.

En cuanto a aspectos ecológicos, ninguno de estos nemátodos es resistente a una rápida pérdida de humedad. Sin embargo, cuando esta se realiza en forma gradual en las condiciones de suelo, permite que las formas infectivas sobrevivan varios días. Las condiciones climáticas, especialmente temperatura, del sitio de donde proceden los nemátodos están muy bien correlacionadas con los rangos óptimos de cada uno de ellos; de ahí la importancia de utilizar nemátodos 
nativos en un programa de control de plagas. No obstante, es bueno considerar que la infectividad ocurre sobre un rango más amplio que la reproducción y desarrollo; con temperaturas bajas los nemátodos pueden ser menos activos y requieren mayores períodos de tiempo para encontrar su huésped.

Los nemátodos son aerobios obligados y el consumo de oxígeno está en relación directa de la temperatura. Algunos factores como $\mathrm{pH}$, fotoperiodo y salinidad pueden ser limitantes para el desarrollo y establecimiento de los nemátodos; los juveniles infectivos son atraídos por los $\mathrm{pH}$ básicos y repelidos por pH ácidos (Jaime et al., 1992).

\section{Metodología}

Para determinar la efectividad del nemátodo entomopatógeno Steinernema carpocapsae sobre Sagalassa valida $W$. se procedió a realizar un experimento que consistió en probar tres dosis o concentraciones de nemátodos/palma, más Endosulfan en dosis de $10 \mathrm{cc} /$ palma, comparados con un testigo sin ningún control.

\section{1 Área experimental}

El área experimental tuvo un tamaño de $1.049 \mathrm{Ha}$, distribuidas en 25 parcelas experimentales de 6 palmas cada una, con una densidad de $143 \mathrm{Palmas} / \mathrm{Ha}$.

\subsection{Unidad experimental}

Cada unidad experimental contó con un número de 3 hileras y 2 palmas por hilera ( 6 palmas por unidad), sembradas a una distancia de $9 m^{*} 9 m$ (sistema de tres bolillos). El área total de cada unidad experimental fue de $419.6 \mathrm{~m}^{2}$. El total de unidades experimentales fue de 25 .

\subsection{Modelo estadístico}

El ensayo de campo se instaló empleando un Diseño Completamente al Azar (DCA), con cinco tratamientos y cinco repeticiones, tomando en cuenta que las condiciones del área eran uniformes $u$ homogéneas. modelo matemático de este modelo es:

$Y i j=\mu+T i+\varepsilon i j$ donde:

Yij = Número de larvas muertas

$\mu \quad=$ Media general de larvas muertas

$\mathrm{Ti}=$ Efecto del $\mathrm{i}$ - ésimo tratamiento

عij = Error experimental en la ij - ésima unidad experimental

\subsection{Tratamientos}

En la investigación se evaluaron 5 tratamientos: 3 de control biológico, 1 de control químico y 1 testigo absoluto sin aplicación. Se realizaron 4 repeticiones.

Los tratamientos fueron los siguientes:

Testigo absoluto, sin aplicación de nemátodos (T1)

Suspensión con 750,000 nemátodos/palma (T2)

Suspensión con 1,500,000 nemátodos/palma (T3)

Suspensión con 2,000,000 nemátodos/palma (T4)

Insecticida químico Endosulfan $10 \mathrm{cc} / \mathrm{palma}$ (T5)

Las suspensiones de nemátodos se aplicaron en una sola ocasión, y el tratamiento químico se realizó en tres ocasiones separadas por un lapso de 20 días, aplicándolo al suelo húmedo.

\subsection{Distribución de los tratamientos}

La distribución de los tratamientos se hizo aleatoriamente, escribiendo en pequeñas notas los códigos de los tratamientos y asignándolos al azar, se procedió a colocarlos en las filas de repartición de las unidades experimentales como se muestra en el ccuadro 1: 
Cuadro 1 Distribución de los tratamientos evaluados de acuerdo al sorteo

\begin{tabular}{|c|c|c|c|c|c|c|}
\hline \multirow{6}{*}{ Bordes } & \multicolumn{5}{|c|}{ Borde } & \multirow{7}{*}{ Bordes } \\
\hline & T5R1 & T3R1 & T1R1 & T2R1 & T5R1 & \\
\hline & T4R2 & T2R2 & T3R2 & T1R2 & T5R2 & \\
\hline & T2R3 & T1R3 & T4R3 & T5R3 & T3R3 & \\
\hline & T1R4 & T5R4 & T2R4 & T3R4 & T4R4 & \\
\hline & T3R5 & T4R5 & T5R5 & T1R5 & T2R5 & \\
\hline \multicolumn{6}{|c|}{ Borde } & \\
\hline
\end{tabular}

\subsection{Variable de respuesta}

El efecto de los tratamientos sobre Sagalassa valida $W$. se determinó contando el número de larvas muertas. Esta información se obtuvo extrayendo $10 \mathrm{Kg}$ de raíces hasta una profundidad de 30 centímetros en una calicata realizada con una pala de desfonde en la base del estípite de cada palma; la calicata tenía $60 \mathrm{~cm}$ de largo por $40 \mathrm{~cm}$ de ancho. Las raíces que extraídas se revisaron, registrando el número de larvas muertas.

Se realizaron cinco evaluaciones cada 30 días (una repetición por lectura), a partir de la primera aplicación en campo, utilizando en cada ocasión dos palmas diferentes dentro de cada tratamiento.

\subsection{Manejo del Experimento}

Los tratamientos biológicos se aplicaron enterrando larvas de Galleria melonella infestadas de nemas entomopatógenos en la base del estípite y alrededor de la palma cubriendo una superficie de $0.40 \mathrm{~m}$ de radio. El promedio de multiplicación de nemátodos por larva de G. melonella es de 350.000, lo que permitió calcular las dosificaciones de acuerdo con la cantidad de larvas utilizadas, estableciendo las siguientes especificaciones: a) para la dosis de 750,000 nemátodos/palma se aplicaron 2 larvas de G. melonella infestadas con nemas; b) para la dosis de $1,500,000$ nemátodos/palma se aplicaron 4 larvas; y c) para la dosis de 2,000,000 de nemátodos/palma se aplicaron 6 larvas.

La aplicación del tratamiento químico se realizó usando una bomba aspersora de acción manual, a una distancia de $50 \mathrm{~cm}$ de la base del estípite de la palma, utilizando un litro de agua por palma.

En cuanto a manejo agronómico, se realizaron todas las prácticas requeridas para el buen desarrollo del cultivo, como control de malezas en coronas, podas, fertilizaciones y cosechas oportunas de los racimos. 


\section{Resultados}

De acuerdo con los promedios de larvas muertas de Sagalassa valida W. obtenidos en cada lectura, se pudo observar que todos los tratamientos tuvieron una repuesta similar a los 30 días después de la aplicación de los mismos (primera lectura).
Sin embargo, con el transcurrir del tiempo cada uno de los tratamientos fue tomando distintas tendencias, como se puede observar en el cuadro 2.

Cuadro 2 Número de larvas muertas por lectura realizada por tratamiento

\begin{tabular}{|l|l|l|l|l|l|l|}
\hline & $\begin{array}{l}\text { Repetición } \\
\text { I }\end{array}$ & $\begin{array}{l}\text { Repetición } \\
\text { II }\end{array}$ & $\begin{array}{l}\text { Repetición } \\
\text { III }\end{array}$ & $\begin{array}{l}\text { Repetición } \\
\text { IV }\end{array}$ & $\begin{array}{l}\text { Repetición } \\
\text { V }\end{array}$ & $\overline{\mathbf{Y}}$ \\
\hline Tratamiento 1 & 2 & 0 & 1 & 0 & 0 & 0.6 \\
\hline Tratamiento 2 & 15 & 11 & 16 & 18 & 16 & 15.2 \\
\hline Tratamiento 3 & 19 & 22 & 24 & 34 & 39 & 27.6 \\
\hline Tratamiento 4 & 17 & 14 & 14 & 19 & 22 & 17.2 \\
\hline Tratamiento 5 & 22 & 26 & 33 & 35 & 44 & 32 \\
\hline SUMATORIA &
\end{tabular}

Fuente: Elaboración propia

En orden de importancia, el tratamiento que mantuvo los niveles más altos de larvas muertas fue el tratamiento con insecticida químico (Endosulfan), que mató 22 larvas a los 30 días, aumentando tal nivel de mortandad a 44 a los 60 días. De los tratamientos con dosis de nemátodos entomopatógenos, el T3 $(1,500,000$ nemátodos/palma), reflejó datos importantes considerando que fue aplicado en una sola ocasión, a diferencia del tratamiento químico que fue aplicado en tres ocasiones, demostrando una tendencia favorable. EI T4 (2,000,000 nemátodos/palma) ocupa la tercera posición, reflejando considerables niveles de mortandad de las larvas.

\subsection{Análisis de Varianza y prueba de medias en Diseño Completamente al Azar (DCA)}

Se procedió a realizar el análisis de varianza (ANDEVA) por medio del programa de acceso libre Infostat, cuyos resultados se presentan en el cuadro 3.
Sin embargo, aunque este tratamiento es el que contiene la más alta concentración de nemátodos no fue el más eficiente. Esto puede ser atribuido al ciclo de vida del nemátodo, que aunque esté en constante reproducción, el medio de inoculación (larvas de Galleria melonella), no es suficiente para satisfacer las necesidades de cantidades altas de nemátodos para luego infestar a las larvas de Sagalassa valida.

En última instancia se sitúan los tratamientos T1 (testigo sin aplicación) y T2 (750,000 nemátodos/palma), demostrando valores no relevantes considerando el nivel de daño a Sagalassa valida con el cual partieron.

EI ANDEVA estimó un valor de $F$ de 22.79 y la $F$ tabulada presenta un valor de 2.866 (Reyes, 2007), por lo tanto existen diferencias significativas entre los tratamientos. Debido a esto se procedió a realizar pruebas de comparación de medias de Tukey cuyos resultados se muestran en el cuadro 4. 
Cuadro 3 Análisis de la varianza para la variable larvas muertas de $S$. valida.

\begin{tabular}{|c|c|c|c|c|c|}
\hline F.V. & S.C. & G.L. & C.M. & F & P - Valor \\
\hline Tratamiento & 2990.24 & 4 & 747.56 & 22.79 & $<0.0001$ \\
\hline Error & 656.00 & 20 & 32.80 & & \\
\hline Total & 3646.24 & 24 & & & \\
\hline
\end{tabular}

Cuadro 4 Prueba de comparación de medias por el método de Tukey

\begin{tabular}{|c|c|c|}
\hline Tratamientos & Larvas Muertas & Clasificación* \\
\hline 5 & 32.00 & \multirow[t]{5}{*}{ A } \\
\hline 3 & 27.60 & \\
\hline 4 & 17.20 & \\
\hline 2 & 15.20 & \\
\hline 1 & 0.60 & \\
\hline
\end{tabular}

Medias con una letra común no son significativamente diferentes $(p>0.05)$

De acuerdo con la prueba de medias, el tratamiento 5 (insecticida químico) es el que mejor resultado produce en cuanto a eliminar larvas de S. valida. Sin embargo, el tratamiento 3 (1.500,000 nemátodos/palma) produce resultados similares estadísticamente, por lo que puede considerarse como una alternativa biológica.

\section{Discusión de resultados}

Se determinó que sí existe una alternativa biológica para el control de las larvas del barrenador de la raíz de la palma aceitera, alternativa que es económicamente viable por el bajo costo de la reproducción de los nemátodos (US\$ 0.20 por larva infestada de G. melonella) y ambientalmente amigable debido a la reducción de productos químicos.

Esta nueva alternativa forma parte del manejo integrado de plagas para la disminución en la aplicación de pesticidas en las plantaciones de palma africana, en las cuales por razones de certificación se deben manejar los cultivos libres de químicos

\section{Conclusiones}

La alternativa biológica mediante el uso de nemátodos entomopatógenos Steinernema carpocapsae en una concentración de un millón y medio de organismos para el control del barrenador de la raíz Sagalassa valida $W$. en la región del valle del Polochic tiene resultados estadísticamente similares al tratamiento químico, con la ventaja de que el tratamiento biológico se aplicó una sola vez, mientras que del químico se hicieron tres aplicaciones.

El sustrato que debe usarse para inocular el nemátodo entomopatógeno en medio in vivo en el campo son las orugas de Galleria melonella, que es una base de cultivo adecuada para el desarrollo de nemátodos y es considerablemente más económico en comparación con el tratamiento químico.

\section{Referencias}

ANCUPA Y SESA, (2007). Inventario de plagas del cultivo de palma aceitera Elaies guineensis Jacq en el Ecuador.

ANCUPA Y FEDEPAL, (1999). Palma africana, una clara alternativa de desarrollo.

Barrios, C. (2004). Evaluación del parasitismo de Heterorhabditis spp, y Diplogasteritus spp, sobre Phillophaga spp, Scaptocoris talpa y Ampedus spp, a nivel de laboratorio e invernadero. CENGICAÑA. 
Calvache, H. Franco, P. Aldana, J. 2000. “Plagas de la palma de aceite en Colombia". CENIPALMA. pp. $51-55$.

Coral, J. 2002. "Sagalassa valida Walker, el barrenador de las raíces de palma en Colombia". CENIPALMA. Pp. $14-21$

Debach, P. 1978. "Control biológico de las plagas de insectos y malas hierbas". México, D. P. Editorial Continental. pp. 607-737.

Duarte, A. et al. (2012). "Análisis de la dinámica de expansión del cultivo de la palma africana en Guatemala: un enfoque cartográfico". Perfil Ambiental de Guatemala 2010-2012. Vulnerabilidad local y creciente construcción de riesgo. Guatemala, IARNA.

GREPALMA. (2013). El cultivo de la palma aceitera en Guatemala. Historia. (En línea) Guatemala. Consultado el 06 de enero de 2014. Disponible en: http://www.grepalma.com

Jaime, A. et al., (1992). Control Microbiano de insectos. Bogotá, Colombia. CENIPALMA

Kaya, S. y R. Gaugler. (1993). Entomopathoge nic nemátodos, anual review of entomology. pp 38; 181-206.

Martignoni, M. E. (1979). "Producción masiva de insectos". Control biológico de las plagas de los insectos y malas hierbas. México, D. F. CECSA. pp. $679-715$.

Olivares, A. (2006). "Los depredadores de Sagalassa valida W". Ecuador. pp. 21-22

Rivadeneira, J. (2000). Coeficientes técnicos y costos por hectárea de las tecnologías de los principales cultivos del Ecuador. INIAP, pp. 89-92.

Reyes, H. (2007). Estadística aplicada. Tegucigalpa.

Rogg, N. (2000). Manual de entomología agrícola. 668 pág.

Sáenz, A. y F. Betancourt. (2006). Biología Hábitats y manejo del barrenador de raíces de palma. Sagalassa válida Walker. Boletín técnico N²0 CENIPALMA.
Sáenz, A. (2005). Patogenicidad y signos en larvas del barrenador de raíces de palma (Sagalassa válida), por nemátodos entomopatógenos. CENIAVANCES.

Sosa, E. (2010). "Reproducción masiva de nematodos y control biológico". Universidad de Manabí.

Valencia, C. (2003). "Manejo Integrado de Plagas en palma de aceite". CENIPALMA, pp. $95-125$. 